\title{
NOTA PELOS CEM ANOS \\ DO ENSINO SUPERIOR DE FILOSOFIA NO BRASIL (1908-2008)
}

\author{
Eduardo Tuffani (UFF) \\ etuffani@vm.uff.br
}

\begin{abstract}
No ano de 2008, os estudos superiores de Filosofia no Brasil completaram um século de existência quase ininterrupta. A Faculdade Eclesiástica de São Paulo iniciou as suas atividades em março de 1908, mas foi de curta duração, pois encerrou os seus trabalhos em 1914. Em julho de 1908, foi instalada a Faculdade Livre de Filosofia e Letras de São Paulo, denominada posteriormente Faculdade de Filosofia, Ciências e Letras de São Bento, depois incorporada à Pontifícia Universidade Católica de São Paulo. Desde 2002, uma nova Faculdade de São Bento vem oferecendo uma licenciatura em Filosofia. A Academia de Altos Estudos, mais tarde Faculdade de Filosofia e Letras, foi instituída em 1916 pelo Instituto Histórico e Geográfico Brasileiro. Entre outros cursos, oferecia um de Filosofia e Letras, mas também foi de curta duração, encerrando as suas atividades em 1921. A Faculdade de Filosofia do Rio de Janeiro funcionou de 1924 a 1937 na então capital federal. Em 1931, foi instalada a Faculdade Paulista de Letras e Filosofia, também contando com curso de Filosofia, não sobreviveu, até onde se sabe, muito além do conturbado ano de 1932. O Instituto "Sedes Sapientiae" foi instalado em 1933, oferecendo, entre outros, um curso de Filosofia. O Instituto também foi incorporado à PUCSP. Em 1934, foi criada a Faculdade de Filosofia, Ciências e Letras juntamente com a Universidade de São Paulo. A FFCL da USP, a partir desse mesmo ano, passou a oferecer o seu curso de Filosofia. Em 1935, fundou-se a Universidade do Distrito Federal, mas o curso de Filosofia, na Escola de Filosofia e Letras, teve início no ano seguinte. A Faculdade Nacional de Filosofia, Ciências e Letras, unidade da Universidade do Brasil, atual UFRJ, Universidade Federal do Rio de Janeiro, só foi instituída em 1939 com a extinção da UDF e a transferência dos seus cursos para a UB. Nessa ocasião, os cursos superiores foram padronizados e assim se mantiveram por cerca de duas décadas. Por volta de 1940, os cursos de Filosofia no Brasil já estavam consolidados, ainda que fossem pouco
\end{abstract}


numerosos. Segundo esta breve introdução, o primeiro curso criado e instalado foi o diocesano da Faculdade Eclesiástica, depois faculdade pontifícia. O curso de Filosofia da PUCSP é o mais antigo em atividade, uma vez que é oriundo da antiga Faculdade Livre beneditina, que chegou a ser agregada à Universidade de Louvain.

Sob o episcopado de D. Duarte Leopoldo e Silva, foi criada a Faculdade Eclesiástica de São Paulo, obra de Mons. Maximiano da Silva Leite. A Faculdade Eclesiástica passou a funcionar regularmente em $1^{\circ}$ de março de 1908 (MENDONÇA, 1952, p. 13). A Faculdade oferecia um curso de Filosofia com duração de três anos e podia conferir o grau de Doutor em Filosofia (Faculdade, abr. 1908, p. 198). Convertido o Seminário Maior de São Paulo em Seminário Provincial, a Faculdade anexa ao Seminário tornou-se uma faculdade pontifícia por meio de decreto do Papa Pio X (apud MENDONÇA, 1952, p. 14), instalada pontificialmente em 14 de junho de $1908^{18}$. Nessa ocasião, o Colégio Doutoral era composto pelos: Chanceler D. Duarte Leopoldo e Silva, Vice-Chanceler D. Miguel Kruse, Reitor Mons. Maximiano da Silva Leite, Secretário P. João Batista de Siqueira e Lente Catedrático P. Sebastião Leme da Silveira Cintra.

De orientação católica, foram professores da Faculdade os padres doutores João Batista de Siqueira (História da Filosofia e Metafísica Especial), Sebastião Leme da Silveira Cintra (Metafísica Geral e Lógica), Joaquim Domingues de Oliveira (Literatura Portuguesa), José Tupinambá da Frota (Filosofia Moral e Sociologia) e o literato Álvaro Guerra (Literatura) (Seminario, jan./fev. 1909, p. 139; MENDONÇA, 1952, p. 25). Como não se dispõe de um programa do curso de Filosofia, nem do quadro de seus professores, torna-se difícil uma exposição mais detalhada. É certo que também atuaram na Faculdade Eclesiástica os monsenhores Francisco de Paula Rodrigues e Charles Sentroul e D. Lourenço Lumini, os três ligados à Faculdade Livre de Filosofia do Mosteiro de São Bento (MENDONÇA, 1952, p. 13). Em 26 de dezembro de 1910, houve a cerimônia de colação de grau dos primeiros bacharéis da Faculdade Eclesiástica (Seminario, jan. 1910, p. 100), realizando-se então o desejo de D. José de Camargo Barros, antecessor de D. Duarte Leopoldo e Silva e

\footnotetext{
${ }^{18}$ Faculdade (jun. 1908, p. 235). Em Mendonça (1952, p. 13), houve um lapso em que se datou o evento para 14 de julho.
} 
idealizador da reforma do Seminário Maior de São Paulo. A Faculdade encerrou as suas atividades em 1914 pois a Arquidiocese privou a Faculdade do seu principal docente, o P. Sebastião Leme da Silveira Cintra (MENDONÇA, 1952, p. 26), após o que se afastaram Mons. Maximiano da Silva Leite e os padres João Gualberto do Amaral e João Batista de Siqueira. A Faculdade Eclesiástica de São Paulo vem citada como "Pontifícia Faculdade de Filosofia e Letras de São Paulo" numa de suas principais fontes (id., ibid.). Infelizmente não foi possível consultar os Statuta Facultatis Ecclesiasticae Sancti Pauli in Brasilia apud Seminarium Provinciale (apud LACOMBE, 1974, p. 152).

A Faculdade Livre de Filosofia e Letras de São Paulo foi uma iniciativa de D. Miguel Kruse, Abade do Mosteiro de São Bento. A Faculdade Livre beneditina teve início no dia 15 de julho de 1908 (Relatorio, 1908, p. 14), quando Mons. Charles Sentroul, formado pela Universidade de Louvain, deu sua primeira aula no curso de Filosofia. Faziam parte do Conselho dos Estudos Universitários o Presidente D. Miguel Kruse, Mons. Francisco de Paula Rodrigues, Conselheiro Manuel A. Duarte de Azevedo, Barão Brasílio Machado e os doutores Adolfo Augusto Pinto, Reinaldo Porchat, José Bonifácio de Oliveira Coutinho e José Brant de Carvalho. Posteriormente, o Dr. Manuel de Alvarenga integrou o Conselho na qualidade de Secretário. $\mathrm{O}$ curso era dado à noite com aulas em francês, sendo ministradas cinco aulas por semana (id., ibid., p. 31). Na Faculdade Eclesiástica, modelada pela Universidade Gregoriana, o ensino se dava por meio da língua latina (MENDONÇA, 1952, p. 25). O programa do curso beneditino era como se segue: $1^{\circ}$ ano (Criteriologia e Psicologia), $2^{\circ}$ ano (Cosmologia, Teodiceia e Metafísica), $3^{\circ}$ ano (Filosofia Moral e História da Filosofia) (Relatorio, 1908, p. 33). Como o curso era de Filosofia e Letras, cumpre esclarecer que por "Letras" eram tratadas "a litteratura em geral e as sciencias historicas e sociaes" (Estatutos, 1909, p. 19). Pouco depois, a Faculdade Livre contou com lentes de História e de Literatura.

No Anuário de 1911, a Faculdade Livre apresentou o seu corpo docente então constituído: Mons. Dr. Charles Sentroul (Filosofia e substituto para Literatura Francesa), Dr. Afonso d'Escragnolle Taunay (História) e D. Miguel Kruse (Literatura). Mais tarde lecionaram Literatura Cônego Manfredo Leite e Literatura Portuguesa 
Mons. Dr. Silveira Barradas. Mantida a duração de três anos para o estudo da Filosofia, a História e a Literatura eram estudadas "cada materia, num só dos tres annos do curso" (Extracto, 1911, p. 12), conferindo-se o título de Bacharel em Filosofia e Letras da Faculdade Livre de Filosofia e Letras de São Paulo (id., ibid., p. 13). Para obter o grau de Doutor, o interessado devia apresentar "dissertação impressa e publicada depois da approvação do 'Conselho dos Estudos Universitarios', ao menos um mez antes da data fixada para a defesa publica" (id., ibid., p. 13-14). Uma vez agregada à Universidade de Louvain, os graduados da Faculdade Livre podiam obter os graus do Instituto Supremo de Filosofia de Louvain (id., ibid., p. 14). Em 1911, houve a conclusão de curso da primeira turma da Faculdade Livre de Filosofia, ocorrendo a colação de grau de Bacharel em Filosofia e Letras em 11 de abril de 1912. Os primeiros bacharéis foram os senhores Alexandre Correia, Carlos de Moraes Andrade, Vicente Rao, Antônio Define, Onofre Ovídio de Albuquerque, Raul Correia da Silva e José Bueno de Oliveira Azevedo (Relatorio, 1912, p. 1920). Em 1914, o Conselho da Faculdade Livre outorgou o grau de Doutor em Filosofia e Letras ao Conde Carlos de Laet ${ }^{19}$. A Faculdade Livre interrompeu as suas atividades em 1917 em razão da Primeira Guerra Mundial, nesse mesmo ano embarcou para a Europa Mons. Charles Sentroul. Os trabalhos foram retomados em 1922 com novo professor de Filosofia, Dr. Leonardo van Acker.

Antes da fundação da Universidade de São Paulo, a primeira com Faculdade de Filosofia, Ciências e Letras instalada ${ }^{20}$, fundaramse a Universidade de Manaus (1909), a primeira Universidade de São Paulo, de iniciativa privada (1911), a Universidade do Paraná (1912), a Universidade do Rio de Janeiro (1920) e a Universidade de Minas Gerais (1927). A USP foi criada em 25 de janeiro de 1934, e a Universidade de Porto Alegre em 28 de novembro desse mesmo ano.

\footnotetext{
19 "Resolveu o Conselho dos Estudos Universitarios, na sua ultima reunião, conferir o gráu de Doutor honoris causa em philosophia e letras, ao illustre jornalista brasileiro, Snr. Conde de Laet, procurando assim galardoar os esforços empregados pelo erudito homem de letras, na defesa dos sãos principios da moral, da justiça e do profundo bom senso." (Collação, 1914, p. 11)

20 O Ministro Francisco Campos, da Educação e Saúde Pública, reorganizou a Universidade do Rio de Janeiro com o Decreto $\mathrm{n}^{0}$ 19.852, de 11 de abril de 1931, fundando uma Faculdade de Educação, Ciências e Letras que nunca foi instituída. A FFCL da USP foi a primeira faculdade oficial de Filosofia.
} 
Das universidades anteriores à USP, só as duas primeiras abriram espaço para as Humanidades, pois as demais reuniam as faculdades tradicionais de Direito, Medicina e Engenharia. Como a legislação para o ensino superior estava por implantar, existindo somente para os cursos tradicionais, cabia à escola secundária a concessão do título formal, o de Bacharel em Ciências e Letras. Por essa razão, as primeiras universidades não investiram, por exemplo, em Filosofia, Letras e Ciências Humanas. Em 17 de janeiro de 1909, fundou-se a Escola Universitária Livre de Manaus (Passos, jul./dez. 1914, p. 71), estabelecida em 15 de março de 1910 (id., ibid., p. 73). A partir de 13 de julho de 1913, passou a ser chamada Universidade de Manaus (id., ibid., p. 86). Entre as unidades da Universidade, havia uma Faculdade de Ciências e Letras, que era uma escola secundária tendo por modelo o Ginásio Nacional (id., ibid., p. 71), assim denominado então o Colégio Pedro II. Pouco depois, a Faculdade de Ciências e Letras deixou de oferecer o curso secundário, passando a se ocupar de um curso preparatório (id., ibid., p. 87-88). A Universidade de Manaus estava ligada ao Ciclo da Borracha, deixando de existir em 1926, quando foi substituída em $1^{\circ}$ de maio pela Associação Vulgarizadora do Ensino, que tomou para si o encargo de algumas unidades remanescentes (Associação, 1927, p. 100). A primeira Universidade de São Paulo foi criada em 19 de novembro de 1911 (Universidade, 1917, p. 5) e inaugurada em 23 de março de 1912 (id., ibid.). Apesar de a sua principal fonte datar de 1917, deve ter se mantido em funcionamento até $1919^{21}$. No que diz respeito às Humanidades, possuía três unidades: Escola Secundária, Escola de Ciências e Letras e Escola Superior de Filosofia, História e Literatura, "escola de cultura transcendente" (Universidade, 1917, p. 7). De nível superior, a Escola de Ciências e Letras ficou sem instalação por falta de público. A Escola Secundária teve frequência (id., ibid., p. 8), reduzindose o número de matrículas com o passar do tempo (id., ibid., p. 113). A Escola Superior para "cultura transcendente" não era uma escola regular nem chegou a funcionar, pois foi substituída em 7 de dezembro de 1914 pela Universidade Popular (id., ibid., p. 115), onde se davam lições públicas e semanais (id., ibid., p. 89), uma verdadeira escola de extensão. $\mathrm{O}$ fato de ter sido uma instituição privada e a

${ }^{21}$ Segundo pesquisa em andamento, vinculada a Tuffani (2007). 
concorrência das faculdades públicas devem ter contribuído para que a primeira USP encerrasse as suas atividades ${ }^{22}$. Tratou-se aqui das duas primeiras universidades brasileiras por terem tentado adequar à legislação vigente os seus cursos ligados às Humanidades e por serem desconhecidas ainda em parte do meio acadêmico.

Mantida pelo Instituto Histórico e Geográfico Brasileiro, a Academia de Altos Estudos foi fundada em 12 de outubro de 1915 e instalada em 25 de março de 1916. Entre os cursos oferecidos pela Academia, havia um de Filosofia e Letras com duração de três anos. O primeiro curso de Filosofia do Rio de Janeiro não formou turma na primeira fase da Academia ${ }^{23}$, depois chamada Faculdade de Filosofia e Letras. Continuação da Academia, a Faculdade de Filosofia e Letras foi inaugurada em 17 de março de 1919, mantendo os seus cursos em atividade até 1921. O programa do curso de Filosofia e Letras era o seguinte: $1^{\circ}$ ano (História da Língua Portuguesa, Dialetologia, Estilística; Psicologia; História da Literatura Antiga, Grega e Latina; História da Literatura Moderna, da Novilatina e da AngloGermânica), $2^{\circ}$ ano (Filologia Comparada das Línguas Românicas; História das Religiões; Estética e História da Arte; História da Literatura Portuguesa e da Brasileira), $3^{\circ}$ ano (Filosofia Geral e História da Filosofia; Economia Política; Filosofia e História do Direito; Sociologia) (Regulamento, 1919, p. 6-7). Dos cursos da Faculdade, só houve conclusão nas turmas de Filosofia e Letras e Ciências Políticas e Sociais (Listas, 1919/1921)). Ao contrário dos dois primeiros cursos superiores de Filosofia, no oferecido pela Faculdade do IHGB, a Filosofia ocupava um espaço mais reduzido, das cinco disciplinas de Letras, no entanto, só três foram ministradas (id., ibid., f. 4). O título de Bacharel em Filosofia e Letras era equiparado ao de Ciências e Letras concedido pelos ginásios oficiais (Regulamento, 1919, p. 24). Quanto ao Doutorado, a Faculdade o regulamentava:

\footnotetext{
22 O estabelecimento da primeira USP provavelmente deve ter feito com que o governo estadual inaugurasse a sua própria escola de Medicina em 1913.

${ }^{23}$ Da primeira fase da Academia, colaram grau os bacharéis em Ciências Políticas e Sociais (Faculdade, abr./jun. 1990, p. 284). Consultados anteriormente, não foi possível fazer uso agora dos Estatutos da Academia de Altos Estudos (Rio de Janeiro: Imprensa Nacional, 1917, 17 p.). O programa do curso de Filosofia e Letras encontra-se às p. 4-5 da obra sem localização. O Regimento interno da Universidade de São Paulo (São Paulo, 1912, 85 p.) ainda não foi consultado pois o único exemplar de que se tem notícia também não foi encontrado.
} 


\begin{abstract}
O gráo e titulo de doutor serão conferidos ao bacharel ou ao professor que apresentar these original, impressa, defendida perante commissão eleita pela Congregação, e por ella approvada [...] Por dous terços dos votos dos professores em exercicio poderá a Congregação conferir o gráo e o titulo de doutor ao professor que tenha prestado relevantes serviços á Faculdade. (Id., ibid., p. 4.)
\end{abstract}

Em 1924, a Faculdade, já com os seus cursos desativados, conferiu o título de Doutor em Filosofia a Afonso Celso de Assis Figueiredo, Presidente do Instituto Histórico e Geográfico Brasileiro (Diploma, 1924). O corpo docente do curso de Filosofia, não levando em conta as disciplinas de Letras, era constituído pelos professores efetivos: Juliano Moreira (Psicologia), Afrânio de Melo Franco (História das Religiões), Luís Betim Paes Leme (Estética e História da Arte), Laudelino Freire (Filosofia Geral e História da Filosofia), Afonso Celso de Assis Figueiredo (Economia Política), Levi Carneiro (Filosofia e História do Direito) e Júlio Afrânio Peixoto (Sociologia) (Faculdade, 1919/1920, p. 869). Posteriormente, José Maria Moreira Guimarães assumiu História das Religiões, e A. de B. Ramalho Ortigão e Jônatas Serrano foram professores interinos respectivamente de Economia Política e de Filosofia e História do Direito (Faculdade, 1921, p. 729).

Segundo Modesto de Abreu, a Faculdade de Filosofia do Rio de Janeiro funcionou de 1924 "até as imediações de 1937" (apud PAIM, 1983, p. 94). Das antigas faculdades de Filosofia, é agora a menos conhecida. Entre os fundadores dessa Faculdade, são citados os doutores Nicanor Nascimento, Washington Garcia e Inácio Raposo e os generais José Maria Moreira Guimarães e Samuel de Oliveira (id., ibid., p. 95). O curso tinha duração de três anos e oferecia as seguintes disciplinas: Antropologia, Metafísica, História da Civilização, Arqueologia, História das Religiões, Moral Comparada, Estética, Sociologia, História da Filosofia, Filosofia do Direito, História da Arte e Teoria do Conhecimento (id., ibid.). Inicialmente, a Faculdade "funcionava na Praça 15 de Novembro, em dependências da Academia de Comércio, cujo prédio pertencia à Cúria Metropolitana" ( $a$ pud id., ibid.). A primeira conclusão de curso se deu em 1926, e a Faculdade "conferia a láurea doutoral mediante defesa e aprovação de uma tese sobre cada uma das matérias do curso" (apud id., ibid.). Também segundo Modesto de Abreu, houve doutorados, inclusive o seu e dos seus colegas, pois ele tornou-se professor dessa Faculdade 
de Filosofia (apud id., ibid.). Não resta dúvida de que a Faculdade existiu, formou turmas, fazendo parte do cenário intelectual do Rio de Janeiro. Merece a Faculdade, entretanto, um estudo mais profundo, sobretudo no que diz respeito ao quadro docente e aos doutorados conferidos. Esse trabalho pode ser difícil, assim como foi a pesquisa para se ter alguma informação acerca da Faculdade Paulista de Letras e Filosofia (TUFFANI, 2007).

Em 1922, a Faculdade Livre de Filosofia e Letras de São Paulo retomou as suas atividades tendo como professor de Filosofia Dr. Leonardo van Acker. Em 1924, Leonardo van Acker era Titular de Metafísica, e Alexandre Correia, Titular de Moral, bacharel pela Faculdade e doutor em Filosofia pela Universidade de Louvain. A Faculdade Livre ofereceu em 1925 o primeiro curso superior de Letras stricto sensu brasileiro, um curso de Filologia Clássica (Latim e Grego) (Relatorio, 1925, p. 20). Alexandre Correia foi o primeiro professor desse curso de Letras, e Leonardo van Acker, o segundo, doutor em Filosofia e também em Letras. Em 1931, a então chamada Faculdade de Filosofia e Letras de São Bento apresentava o seguinte programa no seu curso de Filosofia e Letras: $1^{\circ}$ ano (Introdução à Filosofia, Cosmologia, Psicologia, Filosofia da Belas-Letras, Literatura Luso-Brasileira), $2^{\circ}$ ano (Psicologia, Metafísica, História da Filosofia), $3^{\circ}$ ano (Crítica, Questões Especiais, Moral Geral, Filosofia do Direito) (Regulamento, mar. 1931, p. 99). O título de Bacharel era conferido aos graduados em Filosofia e Letras, e um atestado de conclusão de curso aos formandos em Filologia Clássica, mantendo-se aos interessados o título de Doutor em Filosofia e Letras, conforme regulamentação exposta anteriormente (id., ibid., p. 100).

O Ministro Francisco Campos reformou o ensino universitário com o Decreto $\mathrm{n}^{\circ} 19.851$, de 11 de abril de 1931, instituindo o Estatuto das Universidades Brasileiras (apud LOBO, 1980, p. 42). Antes disso, não havia legislação plena para o ensino superior, daí o atestado para os formandos em Filologia Clássica da Faculdade de São Bento. Com o Decreto n ${ }^{\circ}$ 19.852, de 11 de abril de 1931, o governo federal criou a Faculdade de Educação, Ciências e Letras, que ficou por instalar. A primeira faculdade instalada após o Estatuto foi 
a Faculdade Paulista de Letras e Filosofia em $1^{\text {o }}$ de junho de $1931^{24}$. A Faculdade Paulista vem por vezes citada erroneamente como "Faculdade de Letras e Filosofia de São Paulo" (ISOLDI, 1932, f. de rosto; LACOMBE, 1974, p. 155). Em 27 de novembro de 1930, intelectuais paulistas fundaram a Sociedade de Filosofia e Letras de São Paulo (CAMPOS, 1954, p. 421-422), entidade que deu origem à Faculdade Paulista. O Conselho Superior da Faculdade era composto pelos: Diretor José de Alcântara Machado, Vice-Diretor Ricardo Severo, Secretário Geral Antonio Piccarolo, Consultor Jurídico Spencer Vampré e Tesoureiro Artur Mota (TUFFANI, 2007, f. 7). A Faculdade Paulista oferecia cursos de Letras e de Filosofia, mas o de Letras era um curso de Letras e História, e não de Letras stricto sensu (id., ibid., f. 9). Previa-se a concessão de títulos de Doutor segundo as especialidades ou o conjunto delas oferecido pela Faculdade (id., ibid., f. 8). Pertenciam ao curso de Filosofia as cadeiras obrigatórias de Biologia (Prof. Ulisses Paranhos), Psicologia (Prof. Manuel Bergström Lourenço Filho), Lógica, Estética, Sociologia, História da Educação, História da Filosofia e História das Religiões (id., ibid.). Alguns professores estavam sem cadeira designada por ocasião da abertura dos cursos da efêmera Faculdade. A Faculdade Paulista, ao que tudo indica, não sobreviveu muito além do ano do Movimento Constitucionalista (id., ibid., f. 5).

Em $1^{\circ}$ de março de 1933, tiveram início os trabalhos do Instituto Superior de Pedagogia, Ciências e Letras "Sedes Sapientiae", posteriormente incorporado à Pontifícia Universidade Católica de São Paulo com o nome de Faculdade de Filosofia, Ciências e Letras "Sedes Sapientiae". Fundado pelas cônegas de Santo Agostinho de Nossa Senhora de Jupille, o Instituto "Sedes Sapientiae" era formado pelas seguintes unidades: Faculdade de Letras, Faculdade de Ciências e Instituto Superior de Educação (Instituto (nov. 1935), p. 295). $\mathrm{Na}$ Faculdade de Letras, concediam-se os diplomas de Filosofia, Letras (Letras Clássicas e Vernáculas), História e Geografia e Línguas (Letras Estrangeiras) (id., ibid.). Os cursos tinham duração de três anos, e previa-se curso de Doutorado:

${ }^{24}$ Tuffani (2007, f. 5). Procura-se anotar as datas quando se trata de faculdades ou universidades ainda pouco conhecidas apesar de haver algumas fontes secundárias que já delas trataram. 


\begin{abstract}
A candidata [o corpo discente era feminino] ao diploma de doutora, tendo obtido a licença em qualquer das séries, deverá preparar-se pelo curso especialisado sob a direção de professor catedratico, para defender uma tese. (Id., ibid.)
\end{abstract}

O curso de Filosofia era composto pelas cadeiras de Filosofia, História da Filosofia e Sociologia Geral (id., ibid.). Do curso de Filosofia, eram lentes do Instituto os doutores José Danti (Filosofia Moral), Alexandre Correia (Filosofia e História da Filosofia) e Leonardo van Acker (Filosofia e Filosofia da Educação) (id., ibid., p. 298; CAMPOS, 1941, p. 328).

Fundada em 25 de janeiro de 1934, sob o governo de Armando de Sales Oliveira, a Universidade de São Paulo foi instalada em 11 de março desse mesmo ano. Na Faculdade de Filosofia, Ciências e Letras, faziam parte da Seção de Filosofia as cadeiras de Filosofia, História da Filosofia, Filosofia das Ciências e Psicologia (Anuario, 1934/1935, p. 3). O programa do curso de Filosofia era como se segue: $1^{\circ}$ ano (Filosofia Geral e Psicologia, Sociologia), $2^{\circ}$ ano (Filosofia Geral e História da Filosofia, Filosofia Moral e Social, Sociologia), $3^{\circ}$ ano (Filosofia Geral e História da Filosofia, Lógica e Filosofia das Ciências, Sociologia) (id., ibid., p. 215). Dispondo de uma missão de professores estrangeiros, a FFCL da USP contratou para o curso de Filosofia Étienne Borne e Jean Mauguié, brilhantes professores de liceus parisienses. Étienne Borne assumiu as cadeiras de Filosofia e Psicologia, mas ficou muito pouco tempo à frente do curso de Filosofia, deixando a FFCL em 1935. Jean Maugüé foi responsável pelas mesmas cadeiras e ficou na FFCL de 1935 a 1944, deixando marca profunda nos alunos que formou. É impossível aqui resumir "Certidão de nascimento", capítulo do livro Um departamento francês de ultramar (ARANTES, 1994, p. 61-87). Nesse trabalho, há um longo relato da atividade de Jean Maugüé no terceiro curso leigo de Filosofia stricto sensu criado no Brasil. Não se deve, porém, deixar sem menção algumas linhas que resumem as diretrizes do ensino de Jean Maugüé: "Filosofia não se ensina, quando muito ensina-se a filosofar" (apud id., ibid., p. 63); "O ensino da Filosofia deverá ser principalmente histórico" (apud id., ibid., pp. 71-72). Arrematando as duas citações, chega-se a seguinte lição: "Se é verdade que não se pode jamais ensinar Filosofia a não ser historicamente, como queria Kant, a leitura dos clássicos vem a ser então o único meio de aprender a filosofar." (Apud id., ibid., p. 72.) 
A primeira conclusão de curso se deu em 1936, realizando-se a colação de grau dos primeiros formandos da FFCL em 25 de janeiro de 1937 (Noticiario, 1936, p. 184). Entre os dez graduados em Filosofia, encontravam-se João Cruz Costa e Lívio Teixeira (id., ibid., p. 190), logo a seguir professores assistentes do curso de Filosofia.

A Universidade do Distrito Federal foi concebida por Anísio Teixeira quando Diretor de Instrução Pública do Distrito Federal, no Rio de Janeiro, então capital federal. Entre as suas unidades, estava a Escola de Filosofia e Letras, integrando a Seção de Filosofia as matérias de Filosofia, Filosofia das Ciências, Estética, História da Filosofia, Psicologia e História Geral da Civilização (Prefeitura, 1935, p. 18-19). A UDF se destacava por abrir espaço para os cursos não acolhidos nas universidades que se limitavam a congregar os cursos tradicionais, sendo a única exceção a Universidade de São Paulo. Compunham a UDF as seguintes unidades: Instituto de Educação, Escola de Ciências, Escola de Economia e Direito, Escola de Filosofia e Letras e Instituto de Artes (id., ibid., p. 4). Fundada em 4 de abril de 1935, a UDF foi inaugurada em 31 de julho seguinte. Para o ano de 1935, não havia previsão de oferta do curso de Filosofia, o que só ocorreu em 1936. Também contando com missão estrangeira, a UDF teve como professores Émile Bréhier, da Universidade de Paris, para História da Filosofia (BRÉHIER, 1937, p. 5) e Étienne Souriou, da Universidade de Lyon, para Psicologia e Filosofia (id., ibid., p. 93). A Universidade do Distrito Federal apresentava o projeto mais interessante no que diz respeito às Humanidades, evitando, por exemplo, duplas ou triplas habilitações. Na Seção de Filologia, como inovação, oferecia-se a matéria de Linguística (Prefeitura (1935), p. 19). Iniciativa do então Distrito Federal, a UDF incomodou o governo central com a sua Universidade do Rio de Janeiro, possuidora das mais antigas escolas tradicionais. Quanto ao desfecho da UDF, será tratado ao se referir à instituição da Faculdade Nacional de Filosofia, Ciências e Letras.

Com o Decreto-Lei no 452, de 5 de julho de 1937, a Universidade do Rio de Janeiro sofreu nova reorganização, passando a se chamar Universidade do Brasil. Data da época a criação da Faculdade Nacional de Filosofia, Ciências e Letras. A Faculdade Nacional de Filosofia começou a existir de fato quando o governo federal extinguiu a Universidade do Distrito Federal por meio do Decreto-Lei 
$\mathrm{n}^{\mathrm{o}} 1.063$, de 20 de janeiro de 1939, transferindo para a UB as unidades de ensino da UDF. A FNF ou FNFi foi organizada com o Decreto $\mathrm{n}^{\circ} 1.190$, de 4 de abril de 1939 , e instalada em 21 de julho de $1939^{25}$. Para a segunda missão estrangeira, foi contratado o pensador católico francês René Lucien Poirier. Em meados de 1941, o corpo docente das duas cadeiras de Filosofia era composto por: Maurílio Teixeira Leite Penido, professor contratado, assistentes Celso Lemos e Álvaro Borges Vieira Pinto (Filosofia), Reinhold José Augusto Berge, professor catedrático interino, e René Lucien Poirier, professor estrangeiro contratado (História da Filosofia) ${ }^{26}$. O programa do curso de Filosofia, segundo o Decreto ${ }^{\circ} 1.190$, era assim exposto: $1^{\circ}$ ano (Introdução à Filosofia, Psicologia, Lógica, História da Filosofia), $2^{\circ}$ ano (Psicologia, Sociologia, História da Filosofia), $3^{\circ}$ ano (Psicologia, Ética, Estética, Filosofia Geral) (Fávero (1989), p. 80-81). O Decreto $\mathrm{n}^{\circ} 1.190$ deu início à padronização dos cursos superiores numa ingerência muito infeliz do governo federal. Se o curso de Filosofia não foi tão atingido, nos de Letras e História houve verdadeiras distorções, como o curso de Letras Neolatinas, que habilitava o graduado em francês, italiano, espanhol, latim e português ${ }^{27}$.

Em 12 de novembro de 1940, o Conselho Nacional de Educação reconheceu os cursos de Filosofia, Ciências Sociais, Letras Clássicas e Pedagogia da Faculdade de Filosofia, Ciências e Letras de São Bento, uma vez de acordo com o Decreto $\mathrm{n}^{\circ} 1.190$ (O reconhecimento (nov. 1940), p. vi). Nessa ocasião, faziam parte do corpo docente da segunda faculdade brasileira de Filosofia os professores doutores Alexandre Correia (História da Filosofia e Ética) e Leonardo van Acker (Metafísica, Filosofia da Educação e Lógica) (id., $i$ bid., p. iv). Ao se referir ao reconhecimento da Faculdade de São

\footnotetext{
${ }^{25}$ Leitura obrigatória para a história da FNFi são os Depoimentos, com coordenação de Fávero, Maria de Lourdes de A., Rio de Janeiro: UFRJ, FUJB, 1992, 542 p., (Série Faculdade Nacional de Filosofia, 5).

${ }^{26}$ Reinhold José Augusto Berge vem como "professor catedrático italiano" em Fávero (1989), p. 37, provável lapso por "professor catedrático interino". Conhecido como Frei Damião Berge, tal professor não era italiano, mas natural do Rio de Janeiro, nem havia defendido ainda a sua tese de Cátedra, o que se deu em 1948 para a cadeira de Língua e Literatura Grega, trabalho intimamente ligado à Filosofia (BERGE, 1969).

${ }^{27}$ Um ato ministerial extendeu a habilitação de latim a todos os licenciados em Letras (apud FARIA, 1959, p. 288).
} 
Bento, a Redação equivocou-se pois afirmou que: "A princípio funcionavam somente os cursos de Filosofia e Letras Clássicas" (id., $i$ bid., p. v.). Como foi exposto, o curso de Filosofia data de 1908, e o de Filologia Clássica só foi implantado em 1925.

Com a padronização imposta pelo Decreto $\mathrm{n}^{\circ} 1.190$ e legislação complementar, os cursos mantiveram a duração de três anos, reservando-se um quarto ano para a formação pedagógica, com o que se distinguia o bacharel do licenciado (Anuário, 1939/1949, p. 1516). Na Universidade de São Paulo, por volta de 1940, eram professores do curso de Filosofia Jean Maugüé, João Cruz Costa e Lívio Teixeira. Em 9 de dezembro de 1941, o Conselho Universitário aprovou o regimento para o curso de Doutorado na Faculdade de Filosofia, Ciências e Letras (id., ibid., p. 399). João Cruz Costa se doutorou em 11 de novembro de 1942 (id., ibid., p. 401), e Lívio Teixeira, em 14 de setembro de 1944 (id., ibid., p. 403). Essas duas primeiras teses foram depois publicadas pela FFCL da USP (COSTA, 1942; TEIXEIRA, 1951). A partir de 1942, com a legislação complementar, os cursos superiores estavam padronizados, e outras FFCLs passaram a ser fundadas, divulgando-se o ensino de Filosofia no Brasil. A fase do antigo bacharelado em Ciências e Letras estava encerrada. Buscou-se aqui tratar dos primeiros cursos superiores de Filosofia fundados e instalados no País. Por essa razão, consolidados os cursos, inclusive o de Doutorado, o texto não vai mais além no tempo.

\section{REFERÊNCIAS BIBLIOGRÁFICAS}

ANUARIO da Faculdade de Filosofia, Ciências e Letras. São Paulo: Revista dos Tribunaes, Universidade de São Paulo, 1934/1935.

ANUÁRIO da Faculdade de Filosofia, Ciências e Letras. São Paulo: Universidade de São Paulo, n. 1, 1939/1949.

ARANTES, Paulo Eduardo. Um departamento francês de ultramar: estudos sobre a formação da cultura filosófica uspiana: uma experiência nos anos 60. São Paulo: Paz e Terra, 1994.

ASSOCIAÇÃO Vulgarizadora do Ensino antiga Universidade de Manáos. Almanak Laemmert: Annuario Commercial, Industrial, Agricola, Profissional e Administrativo da Capital Federal e dos Esta- 
dos Unidos do Brasil: Estados do Norte, Rio de Janeiro, ano 83, n. 3, p. 100-101, 1927.

BERGE, Damião, O logos heraclítico: introdução ao estudo dos fragmentos. Rio de Janeiro: Instituto Nacional do Livro, 1969, 452 p.

BRÉHIER, Émile et al. Lições inaugurais da missão universitária francesa durante o ano de 1936. Rio de Janeiro: Universidade do Distrito Federal, 1937.

CAMPOS, Ernesto de Souza. História da Universidade de São Paulo. São Paulo: Saraiva, Universidade de São Paulo, 1954.

. Instituições culturais e de educação superior no Brasil: resumo histórico. Rio de Janeiro: Ministério da Educação, Imprensa Nacional, 1941.

COLLAÇÃO de graus academicos. Annuario da Faculdade Livre de Philosophia e Letras de S. Paulo, S. Paulo, v. 6, p. 11-15, 1914.

COSTA, João Cruz. Ensaio sôbre a vida e a obra do filósofo Francisco Sanchez. São Paulo: Universidade de São Paulo, 1942. 119 p. (Boletins da Faculdade de Filosofia, Ciências e Letras, 29, Filosofia, 1)

DIPLOMA de Doutor em Filosofia conferido a Afonso Celso de Assis Figueiredo pela Faculdade de Filosofia. Rio de Janeiro, 31-121924.

ESTATUTOS da Faculdade Livre de Philosofia e Lettras de S. Paulo. Annuario da Faculdade Livre de Philosophia e Lettras de S. Paulo, São Paulo, v. 2, p. 19-23, 1909.

EXTRACTO dos estatutos da Faculdade Livre de Philosophia e Letras de S. Paulo. Annuario da Faculdade Livre de Philosophia e Lettras de S. Paulo, São Paulo, v. 3, p. 11-15, 1911.

FACULDADE de Philosophia. Boletim Ecclesiastico: Orgam Official da Diocese de S. Paulo, v. 3, n. 10, p. 198-199, abr. 1908.

FACULDADE de Philosophia e Letras. Almanak Laemmert: Annuario Administrativo, Agricola, Profissional, Mercantil e Industrial da Republica dos Estados Unidos do Brasil: Districto Federal, Rio de Janeiro, ano 76, n. 1, p. 869, 1919/1920. 
Almanak Laemmert: Annuario Commercial, Industrial, Agricola, Profissional e Administrativo da Republica dos Estados Unidos do Brasil: Districto Federal, Rio de Janeiro, ano 77, n. 1, p. $729,1921$.

FACULDADE de Philosophia e Lettras. Revista do Instituto Histórico e Geográfico Brasileiro, Rio de Janeiro, v. 151, n. 367, p. 284287, abr./jun. 1990.

FACULDADE Ecclesiastica de S. Paulo. Boletim Ecclesiastico: Orgam Official da Diocese de S. Paulo, v. 3, n. 12, p. 235-237, jun. 1908 .

FARIA, Ernesto. Introdução à didática do latim. Rio de Janeiro: Acadêmica, 1959.

FÁVERO, Maria de Lourdes de A. (Coord.). Projeto ou trama universitária? Rio de Janeiro: UFRJ, 1989. (Série Faculdade Nacional de Filosofia, 1.)

INSTITUTO Superior de Pedagogia, Ciencias e Letras, "Sedes Sapientiae" de São Paulo. Revista Brasileira de Pedagogia: Orgão Oficial da Confederação Catolica Brasileira de Educação, Rio de Janeiro, v. 4, n. 20, p. 295-298, nov. 1935.

ISOLDI, Francisco. Preleções de introdução á historia e critica historica. São Paulo: Faculdade de Letras e Filosofia de S. Paulo, 1932.

LACOMBE, Américo Jacombe. Introdução ao estudo da história da Brasil. São Paulo: Nacional, Universidade de São Paulo, 1974.

LISTAS de alunos que fizeram exames na Faculdade de Filosofia e Letras oriunda da Academia de Altos Estudos. Rio de Janeiro, 19191921, 14 docs.

LOBO, Francisco Bruno. UFRJ: subsídio à sua história. Rio de Janeiro: Universidade Federal do Rio de Janeiro, 1980.

MENDONÇA, Antônio Furtado de. "Reitor e administrador do patrimônio do Seminário Central e Provincial de São Paulo (19041914) e Reitor da Pontifícia Faculdade de Filosofia e Letras de São Paulo (1908-1914)". In: SILVA, Lauro Monteiro de Carvalho e; SILVA, Maximiano de Carvalho e (Orgs.). Monsenhor Maximiano da Silva Leite: 1902 - 28 de outubro - 1952: polianteia comemorati- 
va do $50^{\circ}$ aniversário de sua ordenação sacerdotal. Mogi-Mirim: Cardona, 1952, p. 6-31.

NOTICIARIO. Anuário da Faculdade de Filosofia, Ciências e Letras, São Paulo: Universidade de S. Paulo, p. 84-207, 1936.

PAIM, Antonio. Bibliografia filosófica brasileira. Salvador: Centro de Documentação do Pensamento Brasileiro, 1983, v. 1.

PASSOS, Astrolabio. "Relatorio geral da Universidade de Manáos apresentado á Congregação da mesma Universidade." Archivos da Universidade de Manáos, Manáos, v. 4, n. 3, p. 69-134, jul./dez. 1914.

PREFEITURA DO DISTRICTO FEDERAL. Universidade do Districto Federal. Rio de Janeiro, 1935.

O RECONHECIMENTO dos cursos de filosofia, ciências sociais, letras clássicas e pedagogia. Revista da Faculdade de Filosofia, Ciências e Letras de São Bento, São Paulo, v. 1, p. v-vi, nov. 1940.

REGULAMENTO da Faculdade de Philosophia e Letras: antiga Academia de Altos Estudos. Rio de Janeiro: Imprensa Nacional, 1919.

REGULAMENTO interno da Faculdade de Filosofia e Letras de São Bento. Revista da Faculdade de Filosofia e Letras de São Bento, S. Paulo, v. 4, p. 99-102, mar. 1931.

RELATORIO da Faculdade Livre de Philosophia e Letras de São Paulo. Annuario da Faculdade Livre de Philosophia e Lettras de S. Paulo, S. Paulo, v. 4, p. 11-29, 1912.

RELATORIO do primeiro anno da Faculdade Livre de Philosophia e Lettras de São Paulo. Annuario Faculdade Livre de Philosophia e Lettras, S. Paulo, v. 1, p. 5-34, 1908.

RELATORIO sobre o movimento da Faculdade de Philosophia e Letras, durante o anno lectivo de 1925. Annuario Faculdade de Philosophia e Letras de São Paulo, São Paulo, v. 13, p. 17-20, 1925.

SEMINARIO Provincial. Boletim Ecclesiastico: Orgam Official da Provincia de S. Paulo, v. 5, n. 1, p. 100-3, jan. 1910. 
SEMINARIO Provincial e Faculdade Ecclesiastica. Boletim Ecclesiastico: Orgam Official da Archidiocese de S. Paulo, v. 4, n. 7/8, p. 139-140, jan./fev. 1909.

TEIXEIRA, Lívio. "Nicolau de Cusa: estudo dos quadros históricos em que se desenvolveu seu pensamento e análise dos livros I e II do 'De docta ignorantia'." Revista de História, São Paulo: Sociedade de Estudos Históricos, v. 2, n. 5, p. 19-41, 1951; v. 2, n. 6, p. 283-305, 1951; v. 3, n. 7, p. 71-84, 1951.

TUFFANI, Eduardo. A Faculdade Paulista de Letras e Filosofia: $1^{\circ}$ de junho de 1931. Niterói: Universidade Federal Fluminense, 2007.

UNIVERSIDADE DE SÃO PAULO. Fundação da Universidade de S. Paulo: inauguração official: inicio dos cursos superiores. S. Paulo: Duprat, 1917. 